Manuscript Number :Editorial

Type: Commentary Article

Received date: 04 July, 2020

Accepted date: 11 July, 2020

Published date: 30 July, 2020

\title{
Editorial Highlights for Journal of Vitamins \& Minerals
}

\author{
Sandy Barnabas
}

Department of Food and Nutrition, Riga, Germany

Address for Correspondence:Sandy Barnabas, Deaprtment of Food and Nutrition Riga, Germany Tel : 01222307963; E mail: Sandybarnabas@yahoo.com

I am pleased to introduce Journal of Vitamins \& Minerals (VTE) a rapid peer reviewed Journal which have a key concerns over the Food \& Nutrition which covers the knowledge regarding Micro nutrients, Trace minerals, Probiotics, Multivitamins, Macro nutrients, Vitamins, Beta Carotene, Flavonoids, Biotin, Folic acid, Riboflavin, Mineral density. The Journal features a wide selection of fields in its discipline to form a platform for the authors to make their contribution towards the journal. I am pleased to announce that, all issues of volume 08 were published online well within the time and therefore the print issues were also brought out and dispatched within 30 days of publishing the issue online during the year of 2019.

The Journals aims to higher echelons that enhances the intelligence and information dissemination on topics closely associated with Vitamins \& Minerals that provide a novel forum dedicated to scientists, teachers, student, healthcare professionals to express their research articles, review articles, case reports and short communications on an array of Vitamins \& Minerals research.

All published articles of this journal are included in the indexing and abstracting coverage of Index Copernicus, Google Scholar, Publons, CiteFactor, Electronic Journals Library, RefSeek, Directory of Research Journal Indexing (DRJI), Hamdard University, EBSCO A-Z, Virtual Library of Biology (vifabio), Geneva Foundation for Medical Education and Research, Academic key, OCLC- WorldCat, Open J Gate, SWB online catalogue, Studies receiving funding from a funding organization that is included on the list of PMCand Research Funder Policies or authors having NIH grant were submitted to PubMed.

During the calendar year of 2019, VTE received a total of 18 manuscript, out of which 12 articles (66\%) were rejected in the preliminary screening due to plagiarism or being out of the format and peer review process. During 2019 around 06 articles were subjected for publication after they are accepted in the peer review process. In the 3 issues of Volume 08 published during the year 2019, a total of 06 articles were published (at an average of 2 articles per issue) of which, articles were published from authors all around the world. Globally articles have been accessed by the research scientists and also cited.

During the calendar year 2019, a total of two Editors, seven Reviewers joined the board of VTE and contributed their valuable services towards contribution as well as publication of articles, and their valuable reviewer comments will beneficial to publish quality of article in the Journal.

In order to publish up-to-date, high-quality and original research, VTE aspires to coin a special issue2020 on Coronavirus disease pandemic. Therefore, Editorial Board members of VTE are decided special 
issue title as "Vitamins as immunobooster against corona virus".

I take this chance to acknowledge the contribution of (Dr. Jasminka Ernst) during the final editing of articles published and therefore the support rendered by the editorial assistant, in bringing out issues of VTE in time. I would also like to express my gratitude to all the authors, reviewers, the publisher, the advisory and the editorial board of VTE, the office bearers for his/her support in bringing out one more volume of VTE and look forward to their unrelenting support to bring out the Volume 09 of VTE in scheduled time. 